\title{
LETTERS
}

\section{Creating the conditions that allow health for all to emerge}

The article by Dutton and colleagues alludes to the complexities that determine health and disease. ${ }^{1}$ It has long been known that socioeconomic disadvantage is associated with poor health outcomes, which now can be explained in basic science terms - chronic hypothalamic-pituitaryadrenal axis stimulation resulting in genomic dysfunction. ${ }^{2}$ Indeed, chronic activation of the physiologic stress response is the driver for most morbidities. ${ }^{3}$

The most important message in this article is that even very small changes to a variable in a complex system can have a substantial impact. In this instance, a minuscule increase in social spending results in substantial improvements in avoidable death and an increase in life expectancy.

This type of observation challenges the very nature of health systems. The preoccupation of current health systems with disease management means they should be described as disease management systems. If we really want a health system, the focus needs to be on all factors that have an impact on the emergence of health of individuals and communities; as White and colleagues have shown, on a few occasions, this will require the expert input of disease care. ${ }^{4}$
It is high time to start a public discourse about the pressing need to redesign our health systems. ${ }^{5}$

\section{Joachim P. Sturmberg MBBS PhD}

Family physician and researcher, University of Newcastle, Newcastle, Australia

Cite as: CMAJ 2018 March 26;190:E371. doi: $10.1503 /$ cmaj.69129

\section{References}

1. Dutton DJ, Forest P-G, Kneebone RD, et al. Effect of provincial spending on social services and health care on health outcomes in Canada: an observational longitudinal study. CMAJ 2018;190:E66-71.

2. Cole SW. Human social genomics. PLoS Genet 2014;10:e1004601.

3. Sturmberg JP, Bennett JM, Martin CM, et al. 'Multimorbidity' as the manifestation of network disturbances. J Eval Clin Pract 2017; 23:199-208.

4. White KL, Williams F, Greenberg B. The ecology of medical care. N Engl J Med 1961;265:885-92.

5. Sturmberg JP. Health system redesign. How to make health care person-centered, equitable, and sustainable. Cham (Switzerland): Springer; 2018.

Competing interests: Joachim Sturmberg is the Foundation President of the International Society for Systems and Complexity Sciences for Health. 